\title{
Simulation and Implementation of Grid-connected Inverters
}

\author{
Ahmed Abdalrahman \\ Engineer \\ Dept. of Electronics \& \\ Communications Engineering, \\ Thebes higher institute of \\ Engineering, Cairo, Egypt.
}

\author{
Abdalhalim Zekry \\ Professor \\ Dept. of Electronics \& \\ Communications Engineering, \\ Faculty of Engineering, \\ Ain-shams University, \\ Cairo, Egypt.
}

\author{
Ahmed Alshazly \\ Lecturer \\ Dept. of Electronics \& \\ Communications Engineering, \\ Thebes higher institute of \\ Engineering, Cairo, Egypt.
}

\begin{abstract}
Solar, wind and hydro are renewable energy sources that are seen as reliable alternatives to conventional energy sources such as oil or natural gas. However, the efficiency and the performance of renewable energy systems are still under development. Consequently, the control structures of the gridconnected inverter as an important section for energy conversion and transmission should be improved to meet the requirements for grid interconnection. In this paper, a comprehensive simulation and implementation of a threephase grid-connected inverter is presented. The control structure of the grid-side inverter is firstly discussed. Secondly, the space vector modulation SVM is presented. Thirdly, the synchronization for grid-connected inverters is discussed. Finally, the simulation of the grid-connected inverter system using PSIM simulation package and the system implementation are presented to illustrate concepts and compare their results.
\end{abstract}

\section{General Terms}

Control systems, Embedded systems, Power electronics, Renewable energy.

\section{Keywords}

Grid-connected inverter, synchronous PI controller, SVM, PLL, PSIM.

\section{INTRODUCTION}

Fossil fuels and hydropower along with non-commercial fuels such as firewood are considered the main energy resources in Egypt. However, Because of the growing demand in fossil fuel resources and the resulting environmental effects, Egypt's energy strategy aims to increase the reliance on renewable energy sources, particularly wind and concentrated solar power. Consequently, the national energy plan aims to achieve $20 \%$ of total generated electricity from renewable energy sources by the year 2020 including $12 \%$ from wind energy. This expected to be achieved through establishing grid-connected wind farms and solar photovoltaic (PV) systems [1].

Most of renewable energy technology produces a DC power output. An inverter is needed to convert the DC electric energy from the renewable energy source into AC electric energy. The inverters are either stand-alone [2],[3], or gridconnected [4], In case of grid-connected inverter, the inverter output voltage and frequency should be the same as that of the grid voltage and frequency. Consequently, the control of the inverter should be improved to meet the requirements for grid interconnection.

In [5] it is stated that the control tasks of the grid-connected inverter can be divided into two parts: Input-side controller and Grid-side controller. The control objective on the Inputside controller is to capture maximum power from the input source. However, the control objectives on the Grid-side controller are to control the power delivered to the grid, ensure high quality of the injected power and Grid synchronization.

A number of papers, such as [6], [7], [8], deal with control of the grid side inverter, which use current control loop to regulate the grid current. In other works, the control of the grid-connected inverter is based on two cascaded loops: an internal current loop, which regulates the grid current, and an external voltage loop, which is designed for balancing the power flow in the system [5]. Moreover, control strategies employing an outer power controller and an inner current control loop are also reported [9].

In this paper, a comprehensive study of a three-phase gridconnected inverter with grid side controller is presented. To carry this out, the whole inverter system is modeled and simulated using PSIM simulation package, while taking into consideration the non-ideal behavior of the constituting elements of the inverter. In addition, the practical implementation is provided to verify the simulation results. The paper is organized as follows: the theory of the threephase grid-connected inverter is discussed in Section 2. This consists of the control theory of the grid-side inverter. In addition, the space vector modulation SVM is presented. Moreover, it explains the synchronization method for gridconnected power inverters. Inverter simulation and implementation are provided in Sections 3 and 4 respectively. Finally, Summary and conclusions are provided in Section 5.

\section{THE THEORY OF THE THREE- PHASE GRID-CONNECTED INVERTER}

In order to control three-phase voltage-source inverters (VSI), there are two control strategies: current control and voltage control. The voltage-controlled VSI use the phase angle between the inverter output voltage and the grid voltage to control the power flow. In the current controlled VSI, the active and reactive components of the current injected into the grid are controlled using pulse width modulation (PWM) techniques. A current controller is less sensitive to voltage phase shifts and to distortion in the grid voltage. Moreover, it is faster in response. On the other hand, the voltage control is 
sensitive to small phase errors and large harmonic currents may occur if the grid voltage is distorted. Consequently, the current control is recommended in the control of gridconnected inverter [10].

The current controller of three-phase VSI plays an essential part in controlling grid-connected inverters. Consequently, the quality of the applied current controller largely influences the performance of the inverter system. Many control mechanisms have been proposed to regulate the inverter output current that is injected into the utility grid. Among these control mechanisms, three major types of current controller have evolved: hysteresis controller, predictive controller and linear proportional-integral (PI) controller. Predictive controller has a very good steady-state performance and provides a good dynamic performance. However, its performance is sensitive to system parameters. The hysteresis controller has a fast transient response, non-complex implementation and an inherent current protection. However, the hysteresis controller has some drawbacks such as variable switching frequency and high current ripples. These cause a poor current quality and introduce difficulties in the output filter design [7], [11].

The PI controller is the most common control algorithm used for current error compensation. A PI controller calculates an error value as the difference between a measured inverter output current and a desired injected current to the grid, then the controller attempts to minimize the error between them. The PI controller calculation algorithm involves two separate constant parameters, the proportional constant $\mathrm{Kp}$ and the integral constant Ki. The proportional term of the controller is formed by multiplying the error signal by a $\mathrm{Kp}$ gain. This tends to reduce the overall error with time. However, the effect of the proportional term will not reduce the error to zero, and there is some steady stat error. The Integral term of the controller is used to fix small steady state errors. The Integral term integrates the error then multiplies it by a $\mathrm{Ki}$ constant and becomes the integral output term of the PI controller. This removes the steady state error and accelerates the movement of the process into the reference point.

The PI current control offers an excellent steady-state response, low current ripple, constant switching frequency, in addition to well-defined harmonic content. Moreover, the controller is insensitive to system parameters since the algorithm does not need system models [7]. PI controllers can be applied either in the stationary $(\alpha \beta)$ or in synchronous (dq) reference frame. When the synchronous PI controller is used, the control variables become DC and the PI compensators are able to reduce the stationary error of the fundamental component to zero. This is not the case with PI controllers working in the stationary system, where there is an inherent tracking error of phase and amplitude. Therefore, current control in a synchronous (rotating) reference frame, using PI controllers is the typical solution in the three-phase gridconnected inverters [11].

According to the mathematical model of the grid-connected inverter [8], the output voltages of the inverter in the synchronous (dq) frame are given by

$$
\left[\begin{array}{l}
u_{d} \\
u_{q}
\end{array}\right]=L \frac{d}{d t}\left[\begin{array}{l}
i_{d} \\
i_{q}
\end{array}\right]+R\left[\begin{array}{l}
i_{d} \\
i_{q}
\end{array}\right]+\omega L\left[\begin{array}{c}
-i_{q} \\
i_{d}
\end{array}\right]+\left[\begin{array}{l}
e_{d} \\
e_{q}
\end{array}\right]
$$

where ed and eq are the components of the park transformation of the grid voltage. ud and uq are the components of the park transformation of the inverter output. $\omega$ is the angular frequency of the grid. $L$ is the inductance between the grid-connected inverter and the grid. $R$ is the resistance between the grid-connected inverter and the grid.

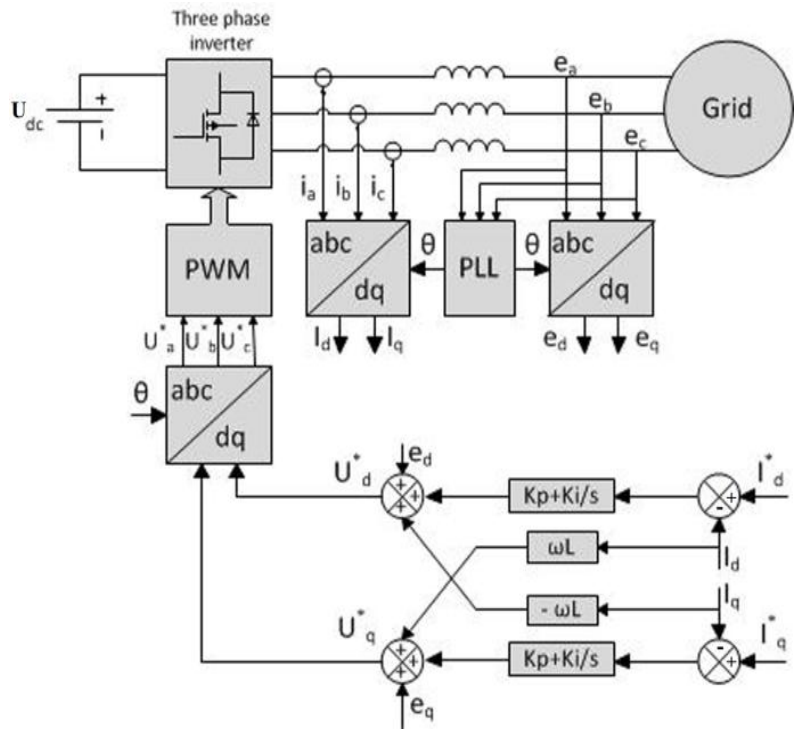

Figure 1 General structure for synchronous controller [6].

The block diagram of the synchronous controller for the gridconnected inverter is represented in Figure 1. We see from the figure that the inverter has two PI controllers to compensate the current vector components that are defined in synchronous reference frame $(\mathrm{dq})$. Because of coordinate transformations, iq and id are DC components and therefore, PI compensators reduce the error(s) between the desired current $\mathrm{I}_{\mathrm{d}}{ }_{\mathrm{d}}\left(\mathrm{I}_{\mathrm{q}}^{*}\right)$ and the actual current $I_{d}\left(I_{q}\right)$ to zero. The output energy and power factor can be controlled via changing $\mathrm{d}$-axis current and q-axis current. For improving the performance of PI controller in such a structure, cross-coupling terms and voltage feed forward are usually used [6].

\subsection{Space vector modulation (SVM)}

After calculating the three-phase reference voltages $\mathrm{U}_{\mathrm{a}}^{*}, \mathrm{U}^{*}{ }_{\mathrm{b}}$ and $U^{*}$ by the current regulation algorithm, the gating pulses for individual inverter switches are generated using the PWM algorithm. Then the desired inverter voltage is generated.

Many PWM techniques have been developed and described during the last few decades and can be found in [12]. However, with microprocessor development, the space vector modulation (SVM) becomes popular and possibly the best PWM technique in three-phase PWM inverter. SVM has many advantages such as constant switching frequency, welldefined output harmonic spectrum, optimum switching patterns, and excellent DC-link voltage utilization [8], [13], [14].

SVM treats the three-phase inverter as a single unit. Specifically, in the case of a two-level inverter as shown in Figure 2, there are eight possible unique states, each of which determines a voltage space vector. As shown in Figure 3, six voltage space vectors shape the axis of a hexagon and divide the whole space into six sectors from 1 to 6 . Moreover, there are two zero vectors, $\mathrm{U}_{0}$ and $\mathrm{U}_{7}$ which lie at the origin. The angle between any two adjacent non-zero vectors is $60^{\circ}$. Therefore, SVM is a digital modulating technique where the objective is to find an appropriate combination of active and zero vectors to approximate a given reference voltage. 


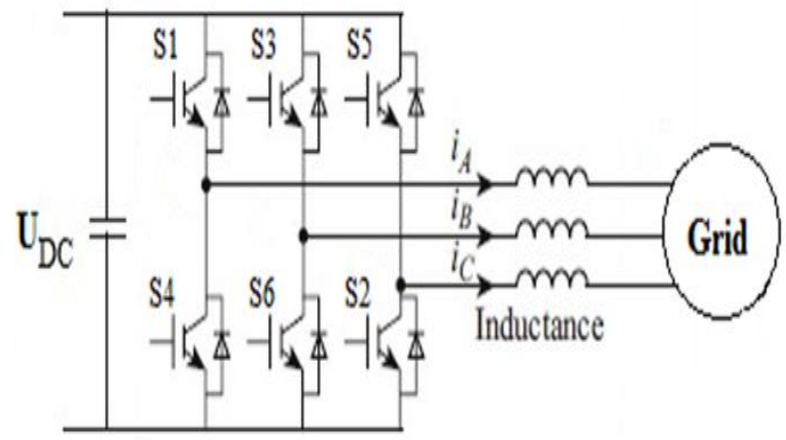

Figure 2 Two-level three-phase inverter configuration

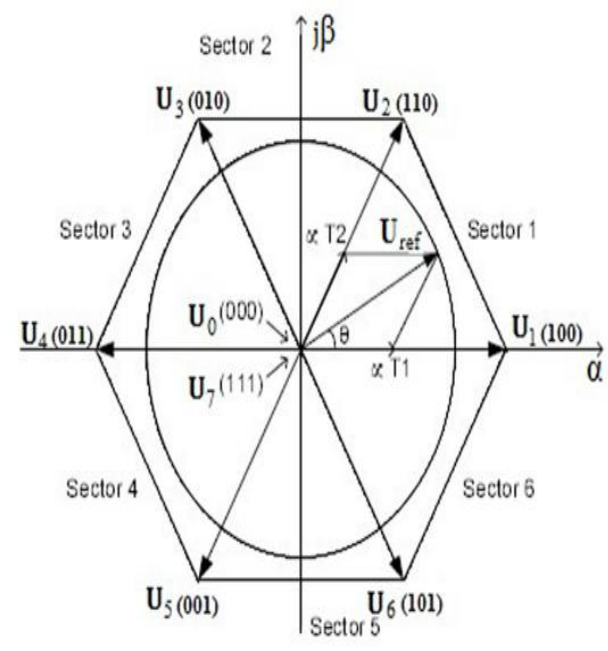

Figure 3 Six active vectors and two null vectors in SVM.

In SVM, the three-phase reference voltages $\mathrm{U}_{\mathrm{a}}{ }_{\mathrm{a}}, \mathrm{U}_{\mathrm{b}}{ }_{\mathrm{b}}$, and $\mathrm{U}_{\mathrm{c}}{ }_{\mathrm{c}}$ are mapped to the complex two-phase orthogonal $(\alpha \beta)$ plane. This is known as the Clark's transformation.

$$
\left[\begin{array}{l}
U_{\alpha} \\
U_{\beta}
\end{array}\right]=\left[\begin{array}{ccc}
1 & -1 / 2 & -1 / 2 \\
0 & \sqrt{3} / 2 & -\sqrt{3} / 2
\end{array}\right]\left[\begin{array}{c}
\mathrm{U}_{\mathrm{a}}^{*} \\
\mathrm{U}_{\mathrm{b}}^{*} \\
\mathrm{U}_{\mathrm{c}}^{*}
\end{array}\right]
$$

The construction of any space vector $\mathbf{U}_{\text {ref }}$ which lies in the hexagon can be done by time averaging the adjacent two active space vectors and any zero vectors, as follows

$$
U_{\text {ref }}=\frac{U_{n} * T_{1}+U_{n+1} * T_{2}+U_{0} * T_{0}+U_{7} * T_{7}}{T_{S}}
$$

where $U_{n}$ and $U_{n+1}$ are the non-zero adjacent active vectors. $U_{0}$ and $U_{7}$ are the zero vectors. $T_{1}, T_{2}, T_{0}, T_{7}$ are time-shares of respective voltage vectors and $\mathrm{Ts}$ is the sampling period. SVM can be implemented through the following steps [15]:

1. The Computation of reference voltage and angle $(\theta)$.

$$
\begin{gathered}
\mathrm{U}_{\mathrm{ref}}=\sqrt{\mathrm{U}_{\alpha}^{2}+\mathrm{U}_{\beta}^{2}} \\
\theta=\tan ^{-1} \frac{U_{\beta}}{U_{\alpha}}
\end{gathered}
$$

2. Identification of sector number that is done by taking the angle computed from the last step, and then comparing it with angles range of each sector.

3. Calculate the modulation index $(m)$ and the time duration $\mathrm{T} 1, \mathrm{~T} 2, \mathrm{~T} 0, \mathrm{~T} 7$.

$$
\begin{gathered}
m=\frac{U_{r e f}}{U_{D C} / 2} \\
T_{1}=\frac{\sqrt{3}}{2} T_{s} m \sin (\pi / 3-\theta) ; \\
T_{2}=\frac{\sqrt{3}}{2} T_{s} m \sin (\theta) ; \\
T_{0}+T_{7}=T_{s}-T_{1}-T_{2}
\end{gathered}
$$

4. After $\mathrm{T}_{1}, \mathrm{~T}_{2}, \mathrm{~T}_{7}$, and $\mathrm{T}_{0}$ are calculated; the SVM pulses can be generated. The arrangement of switching sequence must ensure minimum transition between one vector and the next. This method reduces the switching frequency and has fewer harmonics. For sector 1, one can use 01277210 for symmetry reasons as shown in Figure 4.
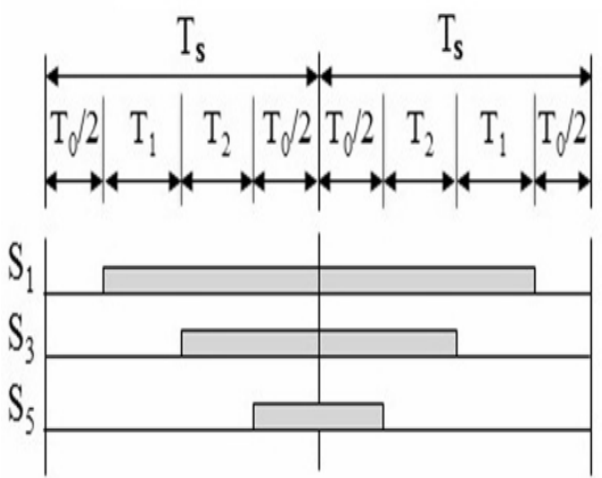

Figure 4 SVM switching patterns for sector 1.

\subsection{Grid synchronization}

The inverter output current that is injected into the utility network must be synchronized with the grid voltage. The objective the synchronization algorithm is to extract the phase angle of the grid voltage. The feedback variables can be converted into a suitable reference frame using the extracted grid angle. Hence, the detection of the grid angle plays an essential role in the control of the grid-connected inverter [5], [6]. The synchronization algorithms should respond quickly to changes in the utility grid. Moreover, they should have the ability to reject noise and the higher order harmonics. Many synchronization algorithms have been proposed to extract the phase angle of the grid voltage such as zero crossing detection, and phase-locked loop (PLL).

The simplest synchronization algorithm is the zero crossing detection. However, this method has many disadvantages such as low dynamics. In addition, it is affected by noise and higher order harmonics in the utility grid. Therefore, this method is unsuitable for applications that require consistently accurate phase angle detection.

Nowadays, the most common synchronization algorithm for extracting the phase angle of the grid voltages is the PLL. The PLL can successfully detect the phase angle of the grid voltage even in the presence of noise or higher order harmonics in the grid. 


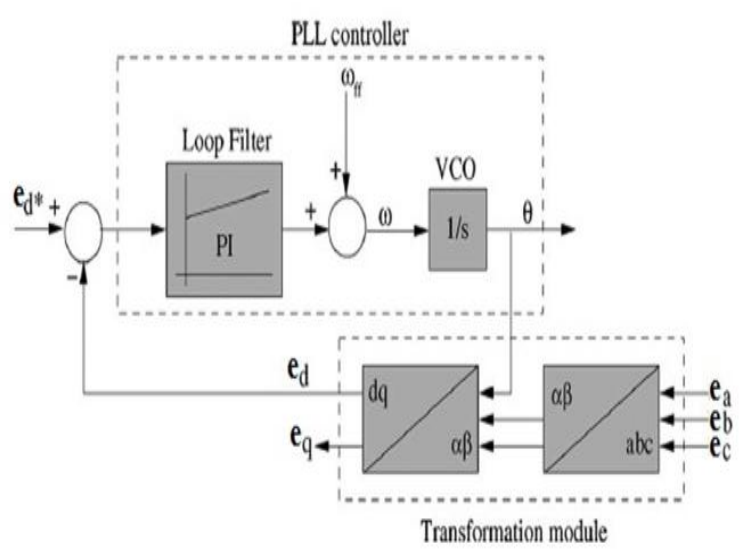

Figure 5 Basic structure of a PLL system for grid synchronization.

As shown in Figure 5, the PLL is implemented in synchronous (dq) reference frame. $e_{a b c}$ is the sensed grid voltage which is then transformed into DC components using park transformation abc-dq. The PLL is locked by setting $\mathrm{e}^{*}$ to zero, which acts as a phase detector. A controller, usually PI, is used to control this variable, which brings the phase error to zero and acts as a loop filter. The $\omega_{\mathrm{ff}}$ represents the utility nominal frequency that is added to the output of the regulator then outputted as the grid frequency. After the loop filter, whose output is the grid frequency, a voltage-controlled oscillator (VCO) is applied. This is usually an integrator, which gives the phase locked angle of the grid $\theta$ as output.

\section{SIMULATION OF GRID CONNECTED INVERTER}

In this section, the intended inverter system is modeled based on the theoretical basics presented in the previous section. The system is then simulated to verify the effectiveness of its control structure and to determine its performance parameters using PSIM simulation package. As shown in Figure 6, the inverter input is $24 \mathrm{~V}$ DC source that represents the output power from renewable energy source. In addition, there is a Three-phase inverter with six MOSFET transistors and six freewheeling diodes. Every transistor has an on-resistance of $0.55-\mathrm{Ohm}$. The connection of an inverter to the utility grid is typically done by the use of a grid filter. The objective of the grid filter is to attenuate harmonics in the output voltage of the inverter.
In the simulation model, an LC-filter is utilized as that used in the practical circuit to be able to compare the simulation results with the experimental ones. So, $5 \mathrm{mH}$ inductors with an internal resistance of $0.172-\mathrm{Ohm}$ resistance and $10 \mathrm{uF}$ capacitors are used as an LC-filter in order to achieve the desired voltage and current ripple characteristics [16]. A three-phase step-up transformer is used to achieve isolation, DC decoupling and step-up voltage to $220 \mathrm{~V}$ phase-to-neutral for grid connection. Moreover, three current sensors and three voltage sensors are used to sense the injected current to the grid and grid voltage respectively. Finally, to emulate the utility grid a three-phase $220 \mathrm{~V}, 50 \mathrm{~Hz}$ AC source is used.

\subsection{Simulation of current control structure for grid-connected inverter}

The synchronous PI controller is chosen to be the control structure of the grid-connected inverter as described previously. To simulate the operation of the current control, a step reference input active current $I_{d}$ whose amplitude is $5 \mathrm{~A}$ at time $\mathrm{t}=0.05 \mathrm{~s}$ is applied. Then followed at $\mathrm{t}=0.1 \mathrm{~s}$ by a reactive current reference component step $\mathrm{I}_{\mathrm{q}}$ whose amplitude also is $5 \mathrm{~A}$. The input current waveforms are depicted in Figure 7 (a) and (b). The simulated output inverter current of the inverter model is shown in Figure 7 (c). This figure shows that after a small transient time, the output inverter current reaches its steady state value of $5 \mathrm{~A}$, which is exactly equal to the reference value. On the application of the reactive current step, the output inverter current changed accordingly, as apparent also from the same figure. This proves that the current loop controller is effective such that measured currents track their references. In addition, its dynamic behavior is satisfactory.

\subsection{Simulation of space vector modulation}

Now the simulation of the SVM algorithm is presented. For this purpose, the overall simulation circuit of SVM algorithm is shown in Figure 8. As described previously, the SVM algorithm implementation is divided into four steps; the first step is the computation of the reference voltage and angle $(\theta)$. The waveform of the angle $(\theta)$ is shown in Figure 9 (a). The second step in SVM algorithm is to determine the sector of reference signal. That is done by comparing the angle computed previously with the angle range of each sector by using six comparators. The output of each comparator is high (value $=1$ ) when the angle computed previously is higher than the angle range of each sector. The output is low (value $=0$ ) when the angle computed previously is lower than the angle range of each sector. The sector allocation is shown in Figure 9 (b). 


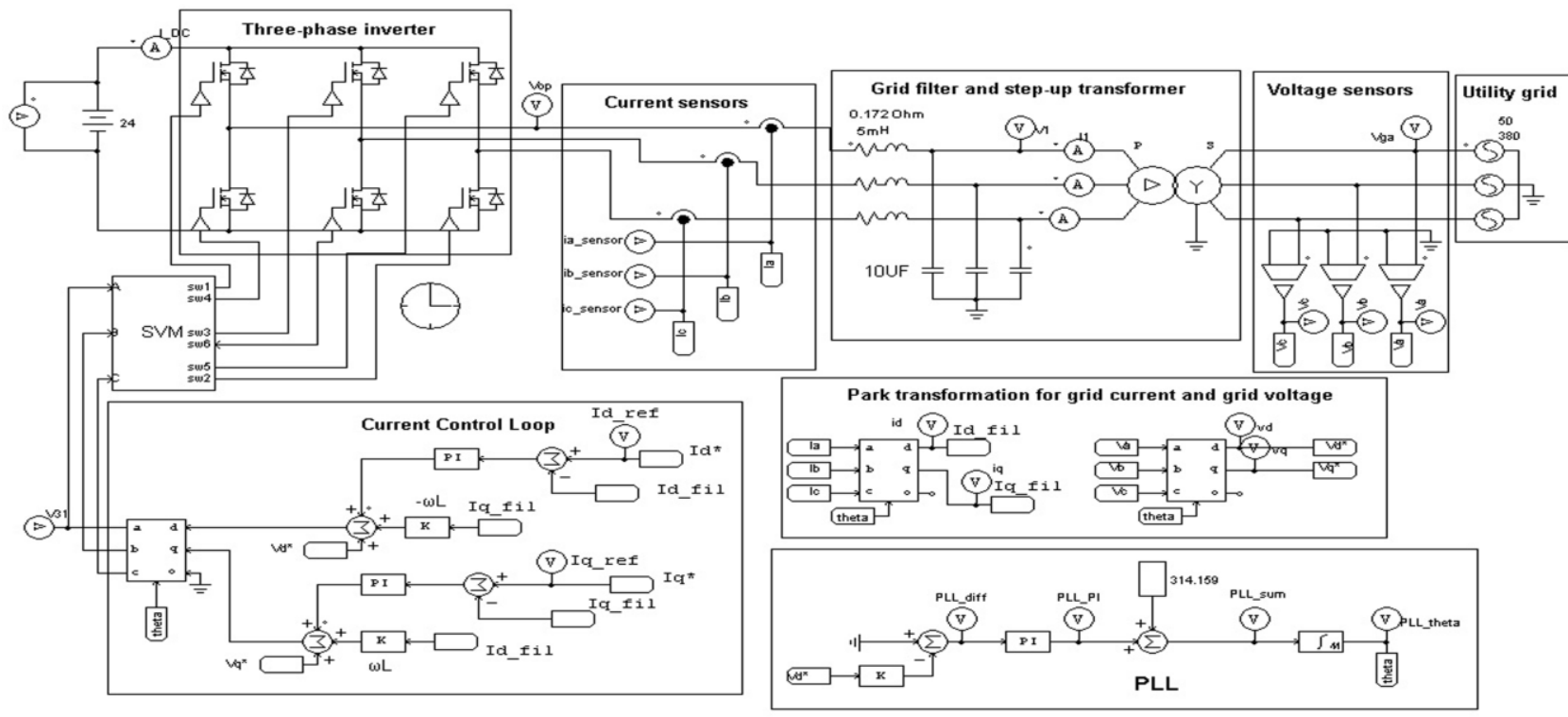

Figure 6 Simulation model of the grid-connected inverter

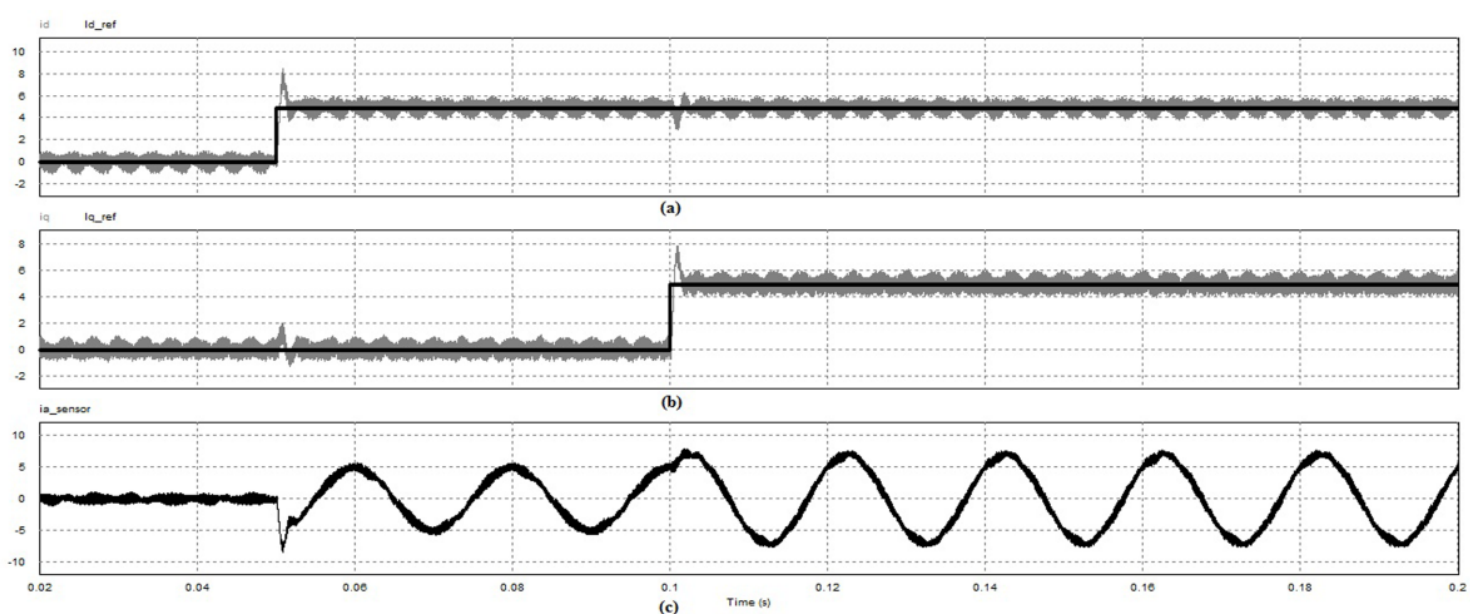

Figure 7 (a) Id current reference and measured (b) Iq current reference and measured (c) Simulation result of phase grid current Ia.

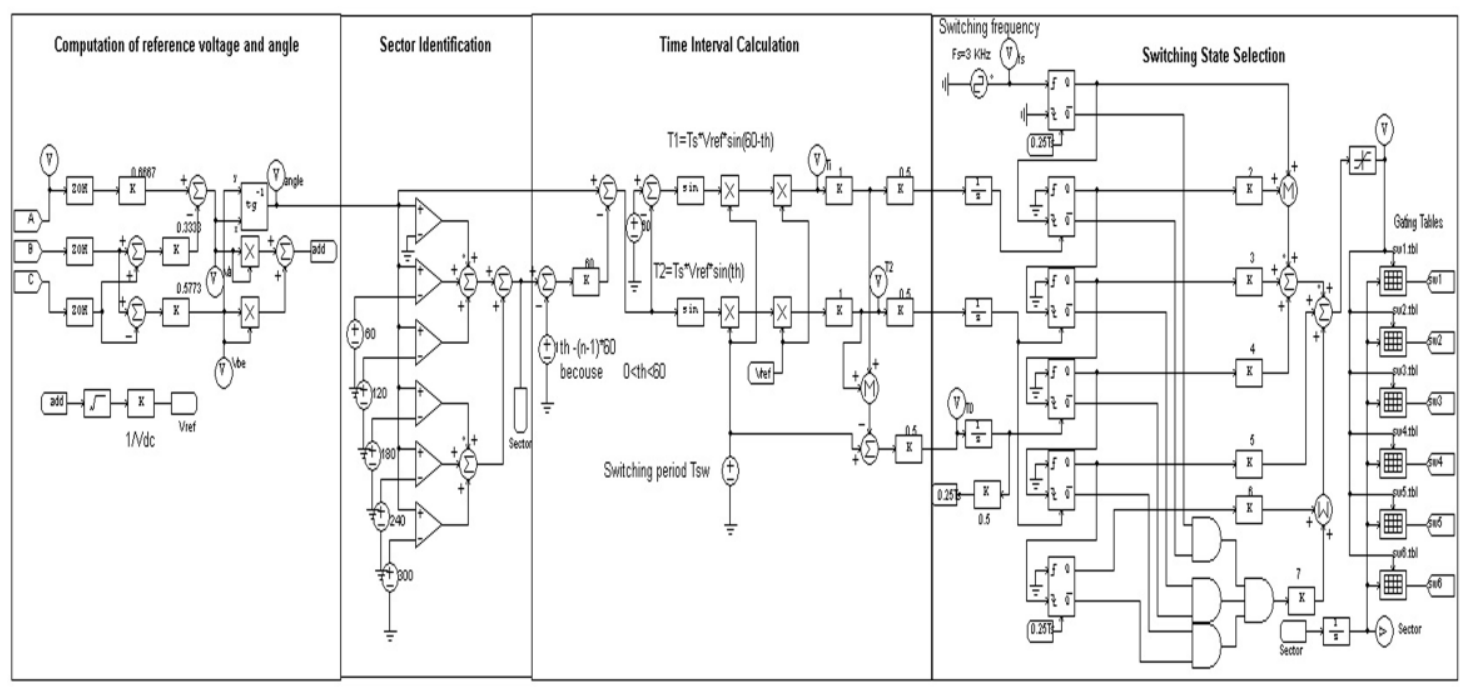

Figure 8 The overall simulation circuit of SVM algorithm 


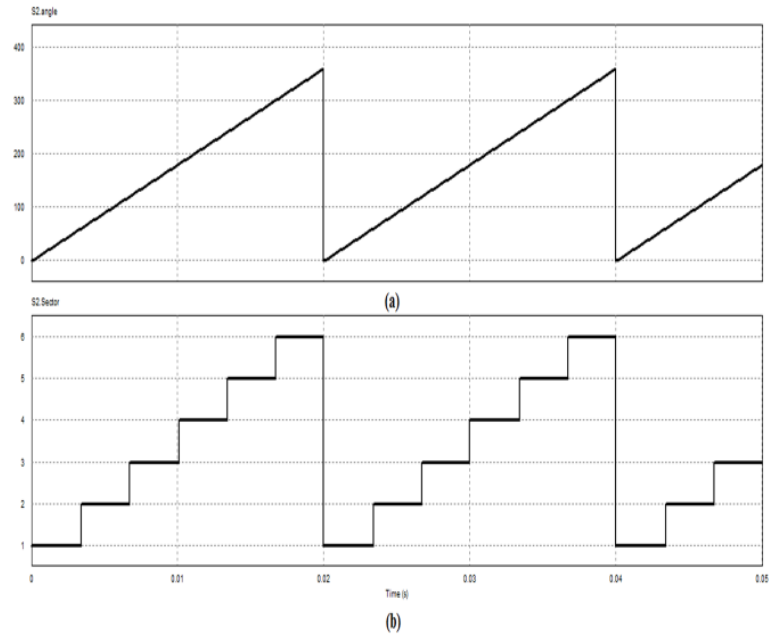

Figure 9 (a) angle calculation (b) Sector allocation

The third step in SVM algorithm is to calculate the time durations $T_{1}, T_{2}, T_{0}$ and $T_{7}$. The time duration is calculated by a set of equations that are a function of modulation index $(m)$, angle $(\theta)$ and sampling frequency $(\mathrm{Fs}=1 / \mathrm{Ts}$ ) which is 3.6 $\mathrm{KHz}$. The final step is to determine the pulse width for each transistor input. The circuit contains six-monostable multivibrators with adjustable width that allows the pulse width to be specified externally. Each pulse with the specified width that is calculated from the previous step is marked by unique amplitude. Then, six two-dimensional lookup tables are used to output the switching pulse for each transistor.

Assuming ideal transistor switches with zero on resistance, the simulated output phase-to-neutral voltage of the gridconnected inverter before LC-filter is shown in Figure 10. This waveform is typical for such an inverter. To demonstrate the effect of the filter, the output voltage waveform of the inverter after the LC-filter is shown in Figure 11. This figure shows that the waveform is a nearly pure sinusoidal waveform with small ripples.

Then, in order to take into consideration the non-ideal effects of the model component, especially the on resistances of the transistors, the simulation is repeated with an on resistance of $0.55 \mathrm{Ohm}$. The simulated waveform of the output phase voltage is shown in Figure 12. It is clear from the figure that the presence of an appreciable on resistance with the power switches causes noticeable distortion of the output voltage waveform.

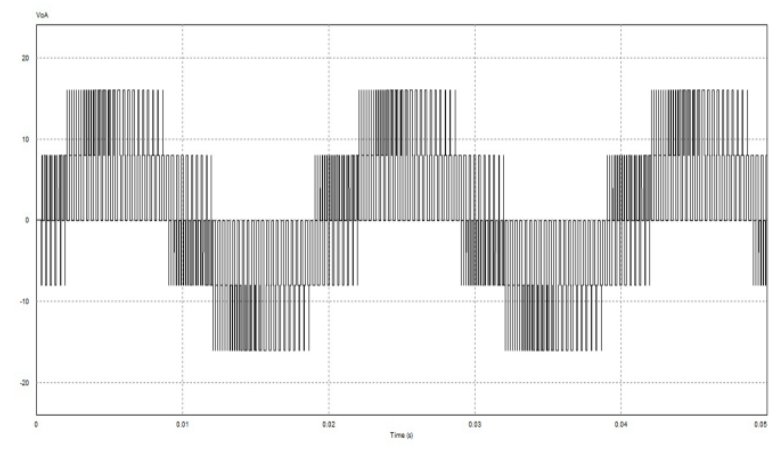

Figure 10 Inverter phase voltage at the input of the filter.

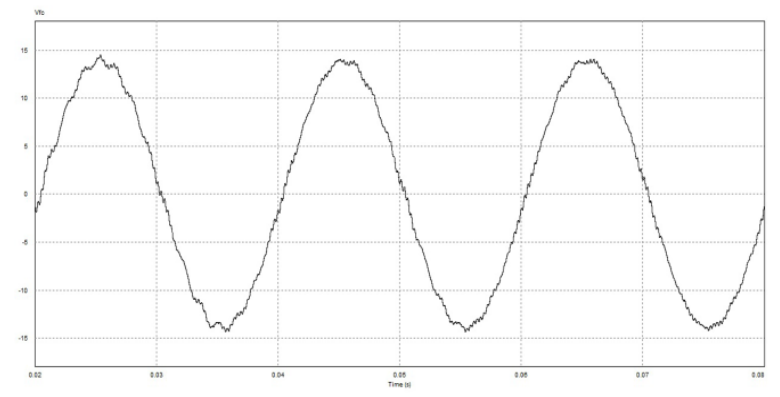

Figure 11 Inverter phase voltage considering ideal transistors.

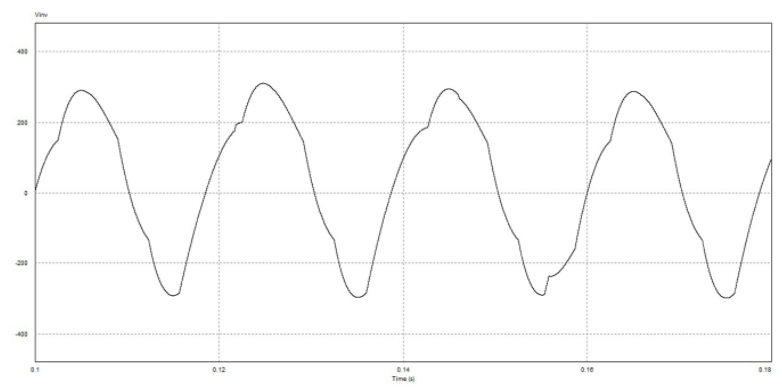

Figure 12 Inverter phase voltage considering non-ideal transistors

\subsection{Simulation of PLL synchronization} circuit

As described previously, the PLL circuit is the best-known synchronization algorithm. The simulation results of PLL as shown in Figure 13 show that the PLL can successfully extract, without errors, the phase angle of the grid voltages, which allows for synchronization with the grid. The extracted phase angle is used to convert the feedback variables into the (dq) reference. Consequently, synchronization between output of inverter phase and grid phase angle is achieved by locking PLL for every instant of time between 0 to $2 \pi$. 

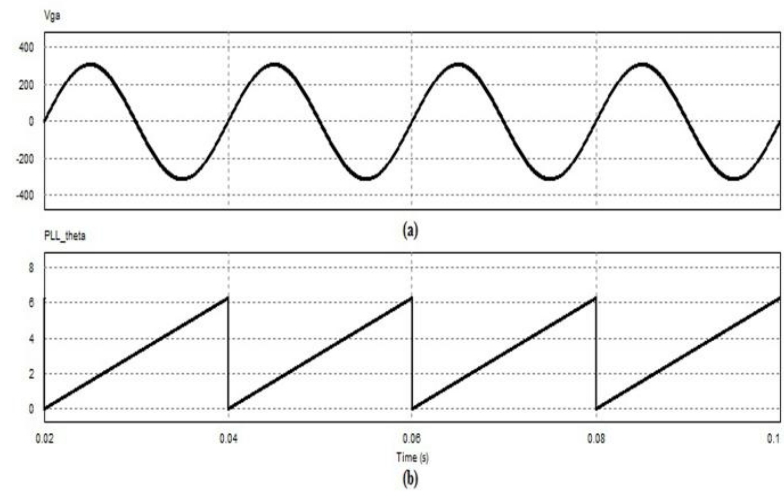

Figure 13 (a) phase voltage of the grid. (b) PLL phase angle.

\section{EXPERIMENTAL}

\section{IMPLEMENTATION OF GRID-} CONNECTED INVERTER

In this section, a complete experimental version of the modeled inverter is presented. The major differences between the simulation model and the experimental version are intended to clarify. The hardware of the grid-connected inverter platform will consist of two sections: the power circuit and the control circuit. The power circuit consists of the power switches and their drivers. On the other hand, the control circuit consists of the dsPIC microcontroller with the software of operation. The following two sections provide a detailed description of each part:

\subsection{Three phase power inverter circuit}

Figure 14 shows the power section of the inverter. It consists of six IRF740 MOSFET transistors with 0.55 -Ohm drain to source on resistance and can handle up to $400 \mathrm{~V}$ and $10 \mathrm{~A}$; along with three IR2 110 high and low side drivers that convert the $5 \mathrm{~V}$ logic level signals from the dsPIC microcontroller to the power MOSFETs level of operation. Additionally, it contains six freewheeling diodes.

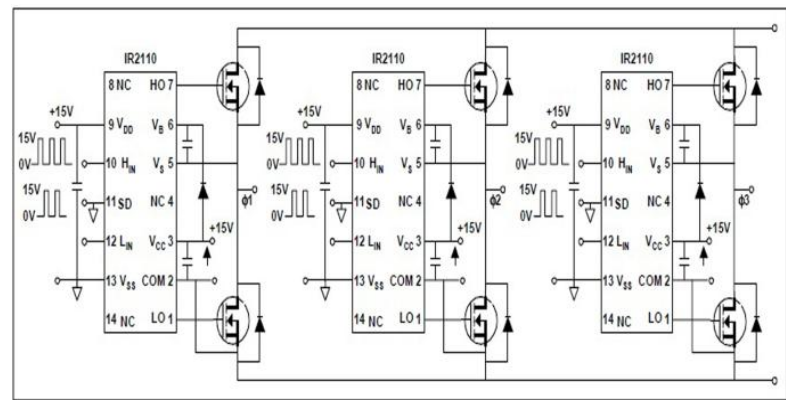

Figure 14 Circuit diagram of power circuit of the inverter

\subsection{The control circuit}

The control circuit consists of the dsPIC30F3010 microcontroller with the software of operation. The software implementation of grid-connected inverter controller is explained in the flow chart in Figure 15. The grid voltage and the current injected to the grid will be sensed firstly through 10-bit analog-to-digital module ADC of dsPIC. Then the grid angle is extracted by PLL algorithm. After that, the PI controller is executed for the current control loop. Finally,
SVM is executed then the gating signals to the power circuit are generated through PWM module of dsPIC. The power semiconductor switches are operated with a switching frequency Fs $=3.6 \mathrm{kHz}$ and a dead time of $4 \mu \mathrm{s}$. The dead time is the period of time that must be inserted between the turn-off event of one transistor in a complementary pair and the turn-on event of the other transistor. This is a precaution to avoid short circuits across the input power supply voltage. A typical oscilloscope snapshot of the control voltage pulses for the two transistors S1 and S3 is shown in Figure 16.

Figure 17 shows a typical oscilloscope waveform of the phase-to-neutral voltage of our experimental grid-connected inverter taken directly before filter. The experimental waveforms are very similar to the corresponding simulated waveforms. Moreover, typical output voltage of the gridconnected inverter taken after the transformer, and the grid voltage are shown in Figure 18. As is clear from the figure, the inverter output voltage and the grid voltage are the same in amplitude, frequency, and phase except that the waveform shape of inverter is distorted. This waveform is to be compared with that simulated in Figure 12. It is apparent that the two waveforms are identical to a large extent. Consequently, it can be concluded that the major waveform distortion of the output inverter voltage is caused basically by the internal resistances of the power supply and the power transistors. The presence of these parasitic resistances not only dissipates power but also distort the voltage waveform. Therefore, one must design the inverter with the smallest possible parasitic resistances such that the total voltage drop across them is much smaller than the power supply voltage at the peak current of the circuit.

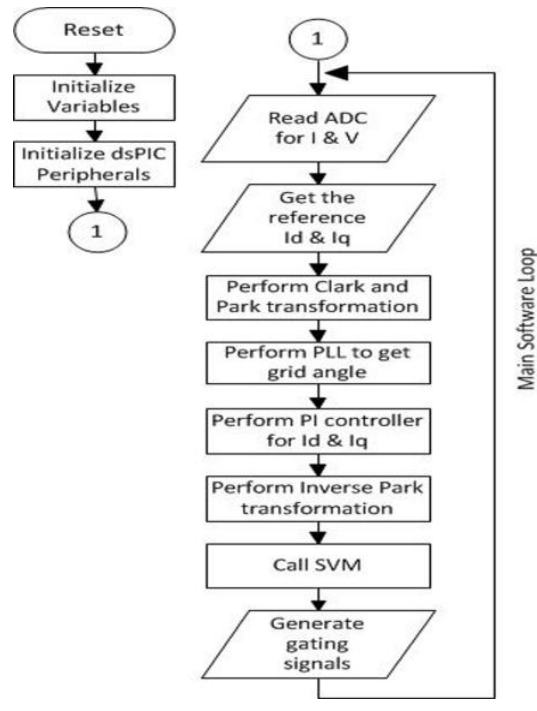

Figure 15 dsPIC software flow chart of the main routine 


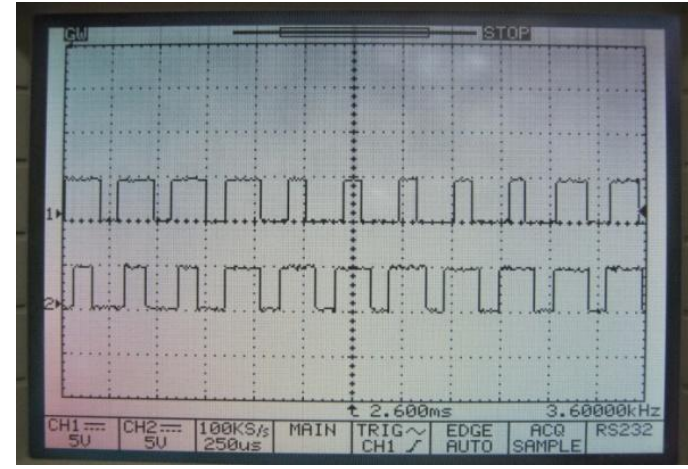

Figure 16 The output pulses for two transistors S1 and S3

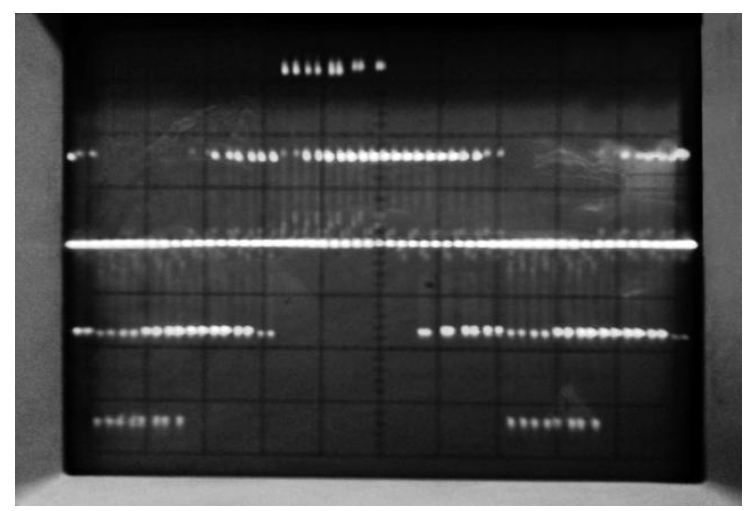

Figure 17 Experiment waveform of the phase-to-neutral voltage of grid-connected inverter

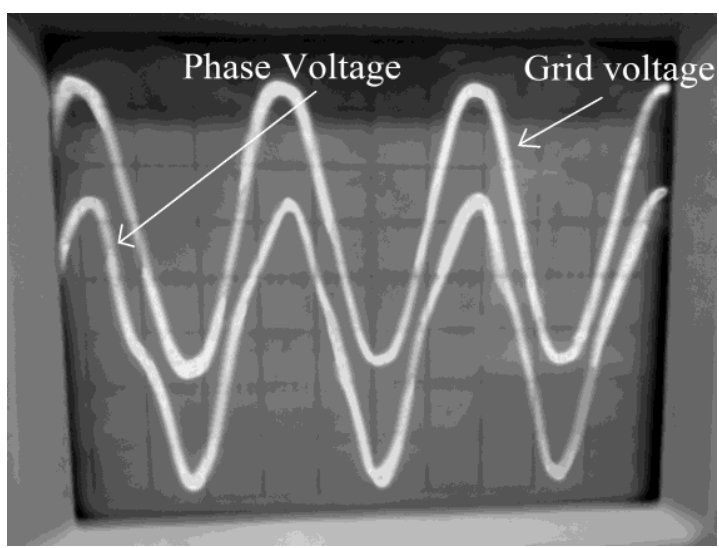

Figure 18 Experimental waveform of the output phase voltage and the grid voltage

\section{CONCLUSION}

The efficiency and the performance of renewable energy sources can be increased by the development of the control structures of the grid-connected inverter. In this paper, the theory of the three-phase grid-connected inverter is outlined. The synchronous PI controller that used to control the injected current to the utility grid is discussed. In addition, the SVM algorithm that considered as the best-known PWM technique is presented. Moreover, the PLL is used for grid synchronization algorithm. Then a complete simulation model for this inverter is presented taking into consideration the parasitic elements of the constituting power components. An experimental version is constructed. Additionally, the differences between the simulation and the experimental results are analyzed. An agreement between the simulation and experimental results is founded when the parasitic resistances of the power components of the inverter circuit are taken into consideration. An important conclusion is that such parasitic resistance causes not only power losses but also a distortion in the output voltage waveform.

\section{REFERENCES}

[1] New and Renewable Energy Authority (NREA), Annual report 2010/2011.

[2] A. Zekry. Computer-aided analysis of stepped sine wave inverters. s.l. : Solar Cells 31, 1991.

[3] A. Zekry, A. A. Slim. Investigations on Stepped sine wave push-pull inverter. Mansoura, Egypt : 12th International Mechanical Power Engineering Conference IMPEC12, 2001.

[4] A. Abobakr , A. Zekry. Three phase grid connected inverter, PhD thesis. Cairo, Eygpt : Ain-Shams university, 2008.

[5] Frede Blaabjerg, Remus Teodorescu, Marco Liserre, Adrian V. Timbus. Overview of Control and Grid Synchronization for Distributed Power Generation Systems. s.1. : IEEE Transactions On Industrial Electronics, October 2006. pp. VOL. 53, NO. 5.

[6] Yilmaz Sozer, David A. Torrey. Modeling and Control of Utility Interactive Inverters. s.l. : IEEE Trans On Power Electronics, November 2009. pp. VOL. 24, NO. 11.

[7] Qingrong Zeng, Liuchen Chang. Study of Advanced Current Control Strategies for Three-Phase GridConnected PWM Inverters for Distributed Generation. Toronto, Canada : IEEE Conference on Control Applications, 2005.

[8] YANG Yong, RUAN Yi , SHEN Huan-qing, TANG Yan-yan, YANG Ying. Grid-connected inverter for wind power generation system. Shanghai, P. R. China : J Shanghai Univ (Engl Ed), 2009.

[9] Milan Prodanovic, Timothy C. Green. Control and Filter Design of Three-Phase Inverters for High Power Quality Grid Connection. s.l. : IEEE Transactions On Power Electronics, January 2003. pp. VOL. 18, NO. 1.

[10] Sung-Hun Ko, Seong R. Lee, Hooman Dehbonei, Chemmangot V. Nayar. Application of Voltage- and Current-Controlled Voltage Source Inverters for Distributed Generation Systems. s.l. : IEEE Transactions On Energy Conversion, September 2006. pp. VOL. 21, NO. 3.

[11] Marian P. Kazmierkowski, Luigi Malesani. Current Control Techniques for Three-Phase Voltage-Source PWM Converters: A Survey. s.l. : IEEE Transactions On Industrial Electronics, October 1998. pp. VOL. 45, NO. 5 .

[12] Muhammad H. Rashid. Power Electronics: Circuits, Devices and Applications (3rd Edition). s.l. : Prentice Hall, 2004. 
[13] Nisha G. K., IAENG, Ushakumari S., Lakaparampil Z. V. Harmonic Elimination of Space Vector Modulated Three Phase Inverter. Hong Kong : international multiconference of engineers and computer scientists, 2012.

[14] A. Mehrizi-Sani, S. Filizadeh. Digital Implementation and Transient Simulation of Space-Vector Modulated Converters. Montreal, QC : Power Engineering Society General Meeting IEEE (PESGM 06), Jun.2006.
[15] D. Rathnakumar, J. Lakshmana Perumal, T. Srinivasan. A New software implementation of space vector $P W M$. s.l. : Proceedings of IEEE Southeast conference, 2005. pp. 131-136.

[16] Marco Liserre, Frede Blaabjerg, Steffan Hansen. Design and Control of an LCL-Filter-Based Three-Phase Active Rectifier. s.1. : IEEE Transactions On Industry Applications, September/October 2005. pp. VOL. 41, NO. 5 . 